\title{
The Norms of Authorship Credit: Challenging the Definition of Authorship in The European Code of Conduct for Research Integrity
}

The practice of assigning authorship for a scientific publication tends to raise two normative questions: 1) 'who should be credited as an author?'; 2) 'who should not be credited as an author but should still be acknowledged?'. With the publication of the revised version of The European Code of Conduct for Research Integrity (ECCRI), standard answers to these questions have been called into question. This article examines the ways in which the ECCRI approaches these two questions and compares these approaches to standard definitions of 'authorship' and 'acknowledgment' in guidelines issued by the International Committee of Medical Journal Editors (ICMJE) and the World Association of Medical Editors (WAME). In light of two scenarios and the problems posed by these kinds of 'real-world' examples, we recommend specific revisions to the content of the ECCRI in order not only to provide a more detailed account of the tasks deserving of acknowledgment, but to improve the Code's current definition of authorship.

Keywords: authorship, acknowledgment, credit, responsibility, accountability, ethics 


\section{Introduction}

The practice of assigning authorship for a scientific publication tends to raise two normative questions: 1) 'who should be credited as an author?'; 2) 'who should not be credited as an author but should still be acknowledged?' (Hosseini 2018). The ways in which these questions are answered can impact upon not only the integrity of a specific piece of research, but the practice of responsible research in general (Steneck 2006). Failing to answer these questions in the right way, for example, by misattribution or the denial of authorship, can result in authorship abuse. Indeed, some experts, who view misattribution as fabrication or falsification of author contributions, have linked the misattribution of authorship to research misconduct (Strange 2008; Marušić et al. 2011).

In this paper, we will, firstly, analyze the way in which authorship credit is specified in the latest version of The European Code of Conduct for Research Integrity (ECCRI) and explain how this account relates to the ECCRI definition of 'good research'. Subsequently, we will compare this account of authorship credit with those from the International Committee of Medical Journal Editors (ICMJE) and the World Association of Medical Editors (WAME). Finally, we will suggest how the ECCRI's approach to attribution can be improved in order to deal with some common issues faced by researchers in the sciences.

\section{The European Code of Conduct for Research Integrity: Authorship and Good Research}

Two editions of The European Code of Conduct for Research Integrity (ECCRI) have been published. The first edition, published in 2011, was a collaborative effort between the European Science Foundation (ESF) and All European Academies (ALLEA) (ALLEA 2011). In 2017, a 
revised version of the code was published in an attempt to address "recent and emerging challenges emanating from technological developments, open science, citizen science and social media" (ALLEA 2017a, para. 1). As a supranational code of conduct (Drenth 2012), the ECCRI is endorsed by institutions and academies of science from more than 40 countries (ALLEA 2017b). More importantly, upon the publication of its first edition, it claimed to "complement existing codes of ethics and may be fit, in some cases, to enhance or supersede those already in operation" (ESF 2010, 6). Also, since it is considered to be applicable "to research in all scientific and scholarly fields" (ALLEA 2017b, 3), it addresses challenges faced by researchers of different disciplines.

The ECCRI defines "good research" in terms of four principles of research integrity:

- Reliability in ensuring the quality of research, reflected in the design, the methodology, the analysis and the use of resources;

- Honesty in developing, undertaking, reviewing, reporting and communicating research in a transparent, fair, full and unbiased way;

- Respect for colleagues, research participants, society, ecosystems, cultural heritage and the environment;

- Accountability for the research from idea to publication, for its management and organization, for training, supervision and mentoring, and for its wider impacts (ALLEA 2017b, 4)

Furthermore, these principles apply to a number of different contexts, including "publication and dissemination" (see Figure 1).

[Figure 1 near here] 
The ECCRI provides eight prescriptions by which researchers should abide in order to produce "good publications":

(1) All authors are fully responsible for the content of a publication, unless otherwise specified;

(2) All authors agree on the sequence of authorship, acknowledging that authorship itself is based on a significant contribution to the design of the research, relevant data collection, or the analysis or interpretation of the results;

(3) Authors ensure that their work is made available to colleagues in a timely, open, transparent, and accurate manner, unless otherwise agreed, and are honest in their communication to the general public and in traditional and social media;

(4) Authors acknowledge important work and intellectual contributions of others, including collaborators, assistants, and funders, who have influenced the reported research in appropriate form, and cite related work correctly;

(5) All authors disclose any conflicts of interest and financial or other types of support for the research or for the publication of its results;

(6) Authors and publishers issue corrections or retract work if necessary, the processes for which are clear, the reasons are stated, and authors are given credit for issuing prompt corrections post publication;

(7) Authors and publishers consider negative results to be as valid as positive findings for publication and dissemination;

(8) Researchers adhere to the same criteria as those detailed above whether they publish in a subscription journal, an open access journal or in any other alternative publication form (ALLEA 2017b, 7). 
When it comes to answering the two normative questions posed at the start of this paper, namely, "who should be credited as an author?" and "who should not be credited as an author but should still be acknowledged?", the second and fourth prescriptions are the most pertinent. These stipulate conditions that need to be met to ensure that authorship and acknowledgment statuses are assigned according to the ECCRI's standards of "good research".

\section{Who Should Be Credited as an Author?}

According to the ECCRI, "all authors agree on the sequence of authorship, acknowledging that authorship itself is based on a significant contribution to the design of the research, relevant data collection, or the analysis or interpretation of the results" [italics added] (ALLEA 2017b, 7). This suggests that an individual should be recognized as an author if (and only if) they have made a significant contribution to specific tasks - research design, data collection, or analysis or interpretation of results. Although traditional approaches to authorship tend to assume a link between being an author and having a role in the writing process (Borenstein \& Shamoo 2015), the ECCRI does not make any mention of writing, drafting or revising the manuscript in its definition of authorship. Accordingly, a contributor could be an author without taking part in the preparation of the manuscript.

By contrast, the ICMJE, whose guidelines are those most commonly adopted by peer-reviewed journals (Fong \& Wilhite 2017), posit the following conditions for authorship attribution:

1. Substantial contributions to the conception or design of the work; or the acquisition, analysis, or interpretation of data for the work; AND

2. Drafting the work or revising it critically for important intellectual content; AND

3. Final approval of the version to be published; AND 
4. Agreement to be accountable for all aspects of the work in ensuring that questions related to the accuracy or integrity of any part of the work are appropriately investigated and resolved (ICMJE 2019, 2).

According to the ICMJE, an individual must not only make a substantial contribution to explicit tasks associated with the research, but, in order to be recognized as an author, contribute to the writing process by either drafting or revising the manuscript for important intellectual content. Furthermore, purported authors are required to approve the final version of the manuscript and agree to be accountable for all aspects of the work.

For comparative purposes, we will consider an additional set of guidelines, namely, those provided by the WAME, the specificity of whose normative requirements lie in between those respectively presented by the ICMJE and the ECCRI. In terms of the requirements for authorship credit, the WAME claims that:

Everyone who has made substantial intellectual contributions to the study on which the article is based (for example, to the research question, design, analysis, interpretation, and written description) should be an author...All authors should approve the final version of the manuscript [italics added] (WAME 2007, para. 2).

In light of these requirements, there are three points to consider. Firstly, whereas the ECCRI and the guidelines produced by the ICMJE make explicit certain research tasks to which an individual must significantly or substantially contribute in order to be recognized as an author (research design, data collection, analysis or interpretation), the account provided by the WAME only provides examples of those tasks that warrant attribution, which leaves some room for considering alternative tasks. Secondly, it seems that this indeterminacy stems from 
the fact that the WAME's conditions of authorship are met through substantial intellectual contributions to the study as opposed to substantial contributions to specific tasks. In other words, according to the WAME, no matter what the task is, so long as an individual's substantial contributions are intellectual contributions, then that individual should be recognized as an author. Thirdly, on the basis that any substantial intellectual contribution is sufficient for authorship credit, it is implied that substantial contributions solely to the writing process are deserving of authorship recognition. This contrasts with the position adopted by the ICMJE, whereby importing intellectual content by drafting or revising the manuscript must be complimented with a substantial contribution to another specific task (see Table 1).

[Table 1 near here]

The differences between these three approaches not only generate different answers to the question of who should be credited with authorship status, but they can also create false or unrealistic expectations if misunderstood or misinterpreted. Given that various tasks and contribution types make up the design of the research, data collection and data analysis, contributions to some of the tasks might not always be perceived as worthy of authorship status.

Firstly, there may be disagreements about what distinguishes a substantial contribution from a substantial intellectual contribution. While the difference between intellectual and nonintellectual contributions is not always very clear, such a distinction is still employed in order to (in part) determine authorship status. For instance, some believe that intellectual contributions involve creativity and originality (Hoey 2000). Others suggest that the "intellectualness" of the contribution should be understood in terms of the uniqueness of the text, "the specificity of its claims and its epistemological status" (Biagioli 2003, 262). Accordingly, those who are not responsible for the "truth of the published claims", may be 
perceived as providing “"only” the conditions of possibility for those claims” (Biagioli 1998, 11). Others still highlight advanced methodological expertise and a contributor's "appreciation of the underlying scientific question or the need to exercise personal judgement" as the criteria that distinguishes intellectual from non-intellectual contributions (Hess et al. 2015, 4). By contrast, non-intellectual contributions often pertain to "fact-gathering" tasks such as "carrying out a series of analyses, collecting certain patient data, or suggesting some standard statistical analyses" (Helgesson 2015, 172). Other examples include routine technical services, referring patients for study, providing reagents, assisting with data collection and assembly or manuscript review (Jones 2003, 249).

Secondly, the three regulatory documents adopt different approaches to manuscript preparation. Although, according to the ICMJE guidelines, being involved in drafting or revising the manuscript is a necessary condition for authorship, neither the ECCRI nor the WAME consider this as a prerequisite for becoming an author. Since the task of writing a publication has traditionally been associated with authorship (Larivière et al. 2016), the differences between the three approaches could lead to further ambiguity and tension in the attribution of authorship credit.

It is important to note that this paper does not seek to clarify the contribution types that deserve authorship credit. Furthermore, it does not attempt to suggest how the debate regarding the conditions of intellectual contributions should proceed. The central claim is that given the different approaches to various contribution types and the kinds of credit they deserve, inconsistencies between the ECCRI and other guidelines could generate conflicting processes of authorship attribution. For instance, a technical or administrative assistant in an international project may refer to the ECCRI's definition of authorship and claim that due to their substantial contribution to some of the named tasks, they deserve authorship credit. If the ECCRI was 
intended to revise the current understanding of how authorship is defined and awarded, this change should be communicated clearly. If, however, the ECCRI was not intended as a document that challenges common approaches to authorship attribution (i.e. those provided by the WAME and the ICMJE), then, as will be shown, authorship descriptions employed in the latest version of the ECCRI will likely complicate an already complex debate.

In order to better illustrate the differences between these three approaches, we will draw conclusions regarding authorship assignment based on two hypothetical scenarios from different disciplines. It is worth mentioning that unlike the ECCRI, which is applicable to research in all scientific and scholarly fields, the guidelines produced by the ICMJE and the WAME are intended for the biomedical sciences. However, due, in part, to the widespread uptake and employment of these guidelines (and those provided by the ICMJE in particular (Claxton 2005)) by medically-oriented publications, publishers in non-medical disciplines have adopted similar authorship criteria. For example, the authorship guidelines provided by the Journal of Occupational and Organizational Psychology - a pertinent journal in the context of the first scenario - mirror the WAME authorship guidelines.1 In addition, the authorship guidelines provided by the Journal of Geophysical Research - a pertinent journal in the context of the second scenario - largely resemble the ICMJE guidelines, requiring substantial contributions to the research project as well as some participation in the writing process. 2

\footnotetext{
1 Both the WAME and the Journal of Occupational and Organizational Psychology place an emphasis on intellectual/scientific contributions. In addition, both organisations do not consider manuscript preparation as a prerequisite for authorship. The Journal of Occupational and Organizational Psychology notes that authorship encompasses "not only those who do the actual writing but also those who have made substantial scientific contributions to a study. Substantial professional contributions may include formulating the problem or hypothesis, structuring the experimental design, organizing and conducting the statistical analysis, interpreting the results, or writing a major portion of the paper. Those who so contribute are listed in the byline" (Journal of Occupational and Organizational Psychology 2019).
}

2 The Journal of Geophysical Research claims that "only individuals who have significantly contributed to the research and preparation of the article should be listed as authors. All of these co-authors share responsibility for submitted articles. While not all co-authors may be familiar with all aspects of the research presented in their article, each should have in place an appropriate process for reviewing the accuracy of the reported results" (American Geophysical Union 2006). Despite requiring all co-authors to share responsibility for the submitted 


\subsection{Scenario 1: Data Collection in a Qualitative Study in Organizational Psychology}

This is a hypothetical scenario focusing on the specific research contributions of two fictional characters; Abigail (a postdoctoral researcher in psychology) and Martin (a departmental administrator). In light of the respective criteria provided by the ECCRI, the ICJME and the WAME, the aim is to determine whether these individuals should be credited with authorship based on their specific contributions to a qualitative study in organizational psychology.

A team of four researchers conducted a qualitative study based on interviews. Initially, they produced a list of 30 prospective research participants. The supervisor provided Martin, the departmental administrator, with the list and asked him to email these individuals with an 'invitation to participate', which had been drafted by the four researchers and approved by the university's research ethics committees. Two weeks after the initial invite was sent, those who had not responded received a reminder. Where no response was forthcoming, a second reminder was sent. Martin was also asked to create and maintain a spreadsheet detailing the participants' names, email addresses, preferred interview types and availabilities. Once Martin had scheduled the appointments, Abigail, one of the four researchers, conducted the interviews using a semi-structured questionnaire. Where it was found that the questions did not fit the circumstances, her knowledge and experience allowed her to improvise and prompt the interviewees with different questions. Once the interviews had been conducted, Abigail and the other researchers analyzed and interpreted the data. Finally, a draft manuscript was

article, the authorship guidelines issued by The Journal of Geophysical Research differ from those provided by the ICMJE in two important ways: firstly, because The Journal of Geophysical Research accepts that co-authors may not be familiar with all aspects of the research, then, by implication, authors cannot be accountable for all aspects of the work; secondly, in place of accountability, The Journal of Geophysical Research requires each author to facilitate "an appropriate process for reviewing the accuracy of the reported results". 
produced by the four researchers and, after several revisions, the final version was published in a peer-reviewed journal.

In this scenario, it is reasonable to claim that the contributions of both Abigail and Martin are significant and substantial contributions to the data collection process. The point being that without these contributions the subsequent tasks would not be possible. Since the ECCRI makes no distinction between those collecting the data and those who support or facilitate the data collection process in a significant way, nor does it specifically disqualify administrative support, it would be reasonable to credit both Abigail and Martin with authorship status. However, because Martin did not take part in the drafting or revision of the manuscript, he should not be recognized as an author according to the guidelines issued by the ICMJE. The ICMJE lists 'general administrative support' as an activity that does not qualify a contributor for authorship. However, it is implied that this prescription is superseded in cases where administrators are able to fulfill all four of the ICMJE's requirements for authorship credit.

With regards to the guidelines issued by the WAME, the question arises as to whether these contributions are, specifically, intellectual contributions. Furthermore, in the case of Abigail, the guidelines issued by the ICMJE require us to determine whether her contribution to the manuscript involves drafting or revising it for important intellectual content. As we have already seen, there is considerable debate regarding the conditions needed to distinguish intellectual contributions from non-intellectual ones. Consequently, if we are to avoid being overly legalistic when considering the meaning of 'intellectual', that is, if we are to avoid subscribing to a fixed definition of the term that leaves little or no room for interpreting the significance of potential 'borderline' cases, then we require some other means by which we can judge whether a substantial contribution is an intellectual contribution. One way to do this is to appeal to the notion of accountability. 
According to Michael Davis, a fundamental feature of accountability in the context of research practices is for contributors to "conduct their research in ways allowing them to give a proper account, whether or not they are ever called upon to do so; we want them always to hold themselves accountable" (Davis 1995, 86). As Davis implies, there is a link between accounting for one's contribution to a project and the intellectual content of that contribution; by giving an account of one's contribution to other researchers it "allows other researchers both to evaluate what you have done as a contribution to their field and to learn from it" (ibid.). According to Davis, it is this kind of "external" accountability and its links to reason-giving processes of intersubjective evaluation and endorsement that allows for the distinction between specifically scientific contributions and "mere fact-gathering" (ibid., 87), which, according to the ICMJE, for example, would likely fall under the category of "general administrative support”. It is for such a reason that David Resnik claims that authors on scientific papers need to be able to be held accountable for their part in the work and the paper as a whole (Resnik 1997).

The point is that when it comes to being held to account in the context of a multi-authored publication, no single contributor is able to determine for themselves whether they should be credited with authorship status. In the case of Abigail, if she provides an account of her contribution that is deemed to be a contribution to the field from which researchers in that field can learn, then it is reasonable to credit her with authorship status. In practice, the supervisor will often judge whether an individual's account of their contribution is appropriate such that their contributions can be characterized as intellectual contributions.

Turning our attention to the conditions of authorship credit provided by the ECCRI, the ICMJE, and the WAME, the ICMJE states that all authors should be accountable for all aspects of the work, including the publication. However, rather than mention accountability specifically in 
the context of authorship credit, the ECCRI, instead, assumes that, unless otherwise stated by the individuals concerned, all authors are fully responsible for the content of the publication. Nevertheless, the ECCRI does mention "accountability" as one of the four central principles of good research practice in general. By contrast, the guidelines issued by the WAME state that although all authors should approve the final version of the manuscript, it is not mandatory for all authors to be familiar with all aspects of the work. Indeed, the WAME require only one author (a "guarantor") to take responsibility for the work as a whole.

If, like Davis, we are to employ processes of holding contributors externally accountable for their respective contributions in order to determine the "intellectualness" of those contributions, then, as Adil Shamoo and Resnik $(2015,98)$ argue, it is vital to distinguish accountability from responsibility. They claim that "a person is responsible for an action if he or she deserved to be praised or blamed for the action" (ibid.). By contrast, "a person is accountable for an action if he or she is obligated to give an account (or justification) of the action and bear the consequences of the action" (ibid.). According to Davis, "the emphasis in accountability seems to be on external accounts; the emphasis in responsibility on internal states (and acts not easily opened to public view)" (Davis 1995, 87). Accountability entails answerability if one is indeed called upon to give an account. However, unlike accountability, meeting standards of responsibility does not entail either being able to give an external account or, indeed, providing such an account. However, according to Davis, for someone to be accountable in an external sense does require that that person is responsible for what they do (ibid., 88).

Based on the employment of the concept of accountability in the respective guidelines, both the ICMJE and the ECCRI provide the means for determining the intellectual content of a contribution without having to resort to an explicit definition of the term "intellectual" or 
necessary and sufficient conditions under which a contribution can be deemed to be “intellectual". By contrast, because the guidelines only require one author to take responsibility for the work as a whole and without any explicit mention of the accountability of purported authors, the WAME can only provide examples of those practices that do not constitute substantial intellectual contributions.

Taking into account the conditions of authorship credit provided by the ECCRI, the ICMJE, and the WAME in Table. 1, Abigail and Martin will be accorded different statuses (see Table 2).

[Table 2 near here]

\subsection{Scenario 2: Data Collection in a Qualitative Study of Sedimentation}

This is another hypothetical scenario. Here, the focus is on the specific research contributions of Jennifer (a marine geologist) and Robbie (a hydrographic surveyor) to a qualitative geological study of sedimentation. Once again, the aim is to determine whether these individuals should be credited with authorship based on their specific contributions in light of the respective criteria provided by the ECCRI, the ICJME and the WAME.

A team of geologists conducted a study of sedimentation in a harbor by carrying out a number of hydrographic surveys. They repeatedly mapped the changes in the water depth and highlighted areas that became less deep over time due to the accumulation of sediments. The supervisor asked Jennifer, a marine geologist, to find the hydrographic dataset for this particular location from the same week for previous years. She was asked to extract the relevant historical data from the archive and to create a Geographic Information System database, which 
details survey dates, seabed terrain models, geographic boundaries, primary equipment and quality factors.

Once Jennifer had produced the database, Robbie, a hydrographic surveyor, conducted weekly hydrographic surveys using the same survey platform and equipment (52 surveys in total). Once the data had been collected, Robbie recorded the information as a digital file and forwarded it to the other members of the research team for processing, analysis and interpretation. Jennifer and Robbie did not take part in the processing, analysis or interpretation of the data. Finally, a provisional 3D time-series animation of seabed change was produced with input from the whole research team (including Robbie and Jennifer). After several revisions, the final animation was rendered and presented at a conference. Subsequently, a manuscript, which contained a report produced by Jennifer, was published in a peer-reviewed journal.

It is reasonable to claim that both the Jennifer and Robbie have made substantial contributions to the data collection process. As a result, according to the ECCRI, both Robbie and Jennifer should be credited with authorship status. Nevertheless, Robbie's contributions are limited to data collection and, therefore, one could claim that he has merely 'performed technical services', which are, according to the guidelines issued by the WAME, insufficient for authorship credit. Furthermore, since Robbie has not taken part in the drafting or revision of the manuscript, then, according to the ICMJE, he would not fulfill the criteria for authorship.

Taking into account the conditions of authorship credit provided by the ECCRI, the ICMJE, and the WAME in Table. 1, Robbie and Jennifer will be accorded different statuses (see Table $3)$.

[Table 3 near here] 


\subsection{Recommendations}

Technical, administrative and managerial tasks are vital for the success of many research projects. If they are substantive, then contributions to these sorts of tasks meet the ECCRI's conditions for authorship credit. In the above scenarios, both Robbie and Martin made significant contributions to the data collection phase. Consequently, on the basis of the ECCRI, both of these individuals can make reasonable claims for authorship status (contrary to the requirements presented in the guidelines issued by the ICMJE and the WAME).

Given the increasing importance of technical, managerial and administrative tasks in science (Charlton 2008; Mongeon et al. 2017), we recommend that the developers of the ECCRI seek to disambiguate the definition of authorship in the ECCRI in order to avoid inconsistent applications and potential misattributions of authorship status. Contrary to the normative standards governing publication ethics, if the developers of the ECCRI believe that a significant contribution to a study need not be, specifically, an intellectual contribution, then those reasons should be made explicit. Alternatively, the conditions for authorship in the ECCRI should be revised in order to make explicit the fact that a purported author's significant contribution should be an intellectual contribution, for which the contributor should be held accountable.

Furthermore, as we have seen, if there is a link between accounting for one's contribution to a project and the intellectual content of that contribution, then, in order to be granted authorship status, an individual will be expected to provide an account of their contribution that other researchers reasonably judge to be a contribution to the field from which they can learn. This suggests that there should be a link between the substantial intellectual contribution and the contents of the publication. As we have seen, Davis suggests that a contributor or a group of contributors can only be held externally accountable for their contribution if they have assumed responsibility for it. Accordingly, if one is to expect a contributor or a group of contributors to 
be externally accountable for the contents of the publication, then they should assume responsibility for that content. The least controversial way for a contributor to assume such responsibility is by explicitly preparing such content. If a contributor assumed responsibility for the publication having been involved in the drafting and revision process, and if that contributor gave (what was deemed by other researchers to be) an appropriate account of their contribution to the publication, it would be unreasonable to claim that their contribution was anything other than an intellectual contribution. However, it is possible for an individual to assume responsibility for a publication without participating in the writing process. For example, the manuscript may have been drafted and revised by a team leader's junior colleagues with the former providing guidance and/or final approval. Alternatively, the team leader may have drafted and revised the manuscript with little or no input from their other team members, who, nevertheless, carried out the study. The point is that so long as an individual assumes responsibility for a publication and is able to provide an account of their contribution that other researchers reasonably judge to be a contribution to the field from which they can learn, then such an individual may reasonably be accorded authorship status. On that basis, our first recommendation is to revise the definition of authorship in the ECCRI as follows:

All authors agree on the sequence of authorship, acknowledging that authorship itself is based on, firstly, a significant intellectual contribution to the design of the research, relevant data collection, or the analysis or interpretation of the results and, secondly, the drafting or revision of the manuscript.

\section{Who Should not be Credited as an Author but Should Still be Acknowledged?}

Another category of contributions concerns those activities that warrant acknowledgment in the publication. Acknowledged names are contributors whose inputs are deemed "not 
significant enough to qualify them as author(s)" (Méndez and Alcaraz 2015, 134). Empirical studies show that in disciplines where this form of credit is common, the number and length of acknowledgments and the mean number of acknowledgments per research paper are growing over time (Cronin 2001; Méndez and Alcaraz 2015). This raises questions about who should be acknowledged in scientific publications and the common tasks that qualify for acknowledgment.

Given the growing importance of editorial and translation contributions to publications produced by non-English speakers (Adams 2009), resource contributions (Larivière 2016) and technical contributions to research projects, many of which seem to warrant 'middle' or 'contributing' author status (Lissoni et al. 2013; Mongeon et al. 2017), the ICMJE and the WAME have sought to specify certain common modes of contribution that, in their view, do not justify authorship. Not only does this prevent undeserved recognition, it helps to manage the expectations of, and disagreements between, contributors when it comes to their status within the publication. According to the ICMJE:

Examples of activities that alone (without other contributions) do not qualify a contributor for authorship are acquisition of funding; general supervision of a research group or general administrative support; and writing assistance, technical editing, language editing, and proofreading. Those whose contributions do not justify authorship may be acknowledged individually or together as a group under a single heading (ICMJE 2019, 3).

Similarly, the WAME specify certain tasks that might warrant individual acknowledgment:

Performing technical services, translating text, identifying patients for study, supplying materials, and providing funding or administrative oversight over facilities where the work was done are not, in themselves, sufficient for 
authorship, although these contributions may be acknowledged in the manuscript (WAME 2007, para. 3).

By contrast, the ECCRI states that:

Authors [should] acknowledge important work and intellectual contributions of others, including collaborators, assistants, and funders, who have influenced the reported research in appropriate form, and cite related work correctly (ALLEA 2017b, 7).

If we interpret the meaning of 'acknowledge' in the same way as it is employed in the respective guidelines produced by the ICMJE and the WAME, that is, as a term that accords a certain status to those contributors that do not fulfill the conditions of authorship credit, then the ECCRI's conditions of acknowledgment raise three specific problems.

Firstly, combined with the ECCRI's conditions for authorship credit, which, as we have seen, render any significant contribution to the design of the research, relevant data collection or the analysis or interpretation of the results as sufficient for authorship, the conditions for acknowledgment include contributions that, according to the ICMJE and the WAME, should be recognized as deserving of authorship credit. For example, if an individual were to undertake 'important work' by making an 'intellectual contribution' solely to the drafting and revision of the publication, then, according to the ECCRI, such a contributor should not be recognized as an author. Instead, they should be acknowledged. Whereas the ICMJE deem the drafting and revision of the manuscript (with important intellectual content) to be a necessary condition of authorship and the WAME consider it to be a sufficient condition (in the case that it is an intellectual contribution), the ECCRI, in principle, does not consider the process of intellectually contributing to the manuscript to be necessary for authorship credit. In authorship terms, the restrictions imposed by the ECCRI's conditions for acknowledgment could result in 
cases of misconduct through abuses such as ghost authorship, denial of authorship and coercive authorship.

The second problem relates more broadly to the general normative standards for authorship. As exemplified earlier, the term "intellectual" tends to be associated with authorship criteria. In other words, specifically intellectual contributions are often considered to be necessary for authorship credit. Contrastingly, in the ECCRI, not only is there no mention of "intellectual" contributions within the criteria for authorship, but contributions of this sort are considered to warrant acknowledgment. Due its unconventional take on the status of the term "intellectual", the ECCRI could be seen to support the conditions for inconsistent attributions, misattributions and authorship abuses.

Thirdly, according to the ECCRI, authors are required to acknowledge the contributions of those who have influenced the research "in appropriate form". Accordingly, in order to determine whether an individual should be acknowledged in the publication, authors are required to discern whether the "form" of the individual's influence on the research was appropriate. Without additional specification, this is a confusing qualifier that makes the ECCRI's prescription for acknowledging non-author contributions even more ambiguous.

\subsection{Recommendations}

If it is the case that the developers of the ECCRI are not using the term 'acknowledge' in the way it tends to be employed in the context of publication ethics, then we recommend that it either clarifies (what it sees as) the meaning of "acknowledge" or adopts a less normativelyloaded term altogether. In addition, if the developers of the ECCRI do, in fact, believe that specifically intellectual contributions should not be mentioned in the criteria for authorship 
credit, we recommend, for the sake of clarity and to seriously reconsider the normative standards governing authorship practices, that it provides reasons for such a commitment. Alternatively, if it is the case that the developers of the ECCRI interpret the meaning of "acknowledge" in the same way as it is employed in the respective guidelines produced by the ICMJE and the WAME, and if there are no good reasons for their commitment to the unconventional appropriation of "intellectual contributions", we recommend that prescription 4 of the authorship section of the ECCRI be revised as follows:

Authors should acknowledge important contributions of those who do not meet the criteria for authorship credit, but who have influenced the reported research through, for example, their administrative, technical, lingual, editorial, supervisory or financial roles.

\section{Conclusion}

While contemporary research practice needs guidelines like the ECCRI, the task of reflecting on their usability is the duty of the research community. Without deluding ourselves into thinking that the aforementioned guidelines are inviolable, our concern is that the current definitions of authorship and acknowledgment in the ECCRI are likely to generate confusion among users when considered in the light of more established guidelines by the ICMJE and the WAME. As a result, we have recommended specific revisions to the content of the ECCRI concerning its definitions of authorship and acknowledgment. Using authorship guidelines provided by the ICMJE and the WAME, we recommend that references to "contribution" be replaced with "intellectual contribution". In addition, we have recommended that as well as contributing intellectually to the design of the research, relevant data collection, or the analysis or interpretation of the results, authors should be required to contribute to the drafting or 
revision of the manuscript. While we appreciate the ECCRI's aim to remain relevant to a wide range of disciplines, we have also argued for greater specificity concerning some of the more common research tasks that do not qualify their contributors for authorship but should, instead, be acknowledged. These are administrative, technical, lingual, editorial, supervisory and financial support tasks. 


\section{Acknowledgments}

An early draft of this article was presented in September 2018 during the PUBMET conference held in Zadar University. This article has been written during our time at the Institute of Ethics, Dublin City University. We were in receipt of funding from the EnTIRE Consortium (Mapping Normative Frameworks for EThics and Integrity of Research), which is supported by the European Union's Horizon 2020 research and innovation program under Grant Agreement No. 741782. The funders have not played a role in the design, analysis, decision to publish, or preparation of the manuscript.

We are immensely grateful to Richard Hill for helping us with the scenario about geological research. We also wish to thank and acknowledge the valuable feedback offered by the editor and two anonymous reviewers. 


\section{Declaration of interest statement}

The authors have no conflicting interests. 


\section{References}

Adams, Anthony. 2009. "Public Involvement in the Ethics of Research Publications?"

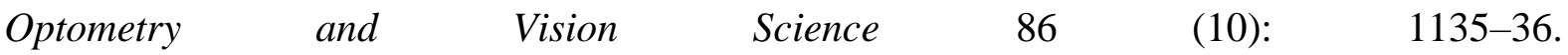
https://doi.org/10.1097/OPX.0b013e3181be4aad.

American Geophysical Union (AGU). 2006. Authorship Guidelines. Accessed June 8, 2019. https://publications.agu.org/files/2012/12/2006EO260009.pdf

All European Academies (ALLEA). 2017b. The European Code of Conduct for Research $\begin{array}{lllll}\text { Integrity-Revised } \quad \text { Edition. } & \text { Accessed }\end{array}$ http://ec.europa.eu/research/participants/data/ref/h2020/other/hi/h2020-ethics_code-ofconduct_en.pdf.

All European Academies (ALLEA). 2017a. "ALLEA Publishes Revised Edition of The European Code of Conduct for Research Integrity." ALLEA News (blog). March 24, 2017. https://www.allea.org/allea-publishes-revised-edition-european-code-conduct-researchintegrity/.

All European Academies (ALLEA), and European Science Foundation (ESF). 2011. The European Code of Conduct for Research Integrity. Accessed January 11, 2019. https://www.allea.org/wp-content/uploads/2015/07/Code_Conduct_ResearchIntegrity.pdf

Biagioli, Mario. 1998. "The Instability of Authorship: Credit and Responsibility in Contemporary Biomedicine." The FASEB Journal 12 (1): 3-16. https://doi.org/10.1096/fasebj.12.1.3.

Biagioli, Mario.2003. "Rights or Rewards?" In Scientific Authorship: Credit and Intellectual Property in Science, edited by Mario Biagioli and Peter Galison, 253-280. New York: Routledge.

Borenstein, Jason, and Adil E. Shamoo. 2015. "Rethinking Authorship in the Era of Collaborative Research." Accountability in Research 22 (5): 267-83. https://doi.org/10.1080/08989621.2014.968277. 
Charlton, Bruce G. 2008. "Figureheads, Ghost-Writers and Pseudonymous Quant Bloggers: The Recent Evolution of Authorship in Science Publishing." Medical Hypotheses 71 (4): 47580. https://doi.org/10.1016/j.mehy.2008.06.023.

Claxton, Larry D. 2005. "Scientific Authorship. Part 2. History, Recurring Issues, Practices, and Guidelines." Mutation Research $589 \quad$ (1): 31-45. https://doi.org/10.1016/j.mrrev.2004.07.002.

Cronin, Blaise. 2001. "Acknowledgment Trends in the Research Literature of Information $\begin{array}{llllll}\text { Science." Journal } & \text { of } & \text { Documentation } & 57 & \text { (3): }\end{array}$ https://doi.org/10.1108/EUM0000000007089.

Davis, Michael. 1995. "A Preface to Accountability in the Professions." Accountability in Research 4 (2): 81-90. https://doi.org/10.1080/08989629508573870.

Drenth, Pieter J. D. 2012. "The European Code of Conduct for Research Integrity." In Promoting Research Integrity in a Global Environment, edited by Tony Mayer and Nicholas Steneck. 161-68. Singapore: World Scientific Publishing Co.

European Science Foundation. 2010. Fostering Research Integrity in Europe. Strasbourg: IREG. Accessed January 11, 2019. https://oeawi.at/wp-content/uploads/2018/09/ESFresearch-integrity-report.pdf.

Fong, Eric A., and Allen W. Wilhite. 2017. "Authorship and Citation Manipulation in Academic Research.” PLOS ONE $12 \quad$ (12): 0187394. https://doi.org/10.1371/journal.pone.0187394.

Helgesson, Gert. 2015. "Scientific Authorship and Intellectual Involvement in the Research: Should They Coincide?" Medicine Health Care and Philosophy 18 (2): 171-75. https://doi.org/10.1007/s11019-014-9585-6.

Hess, Christian W., Christian Brückner, Tony Kaiser, Alex Mauron, Walter Wahli, Uwe Justus Wenzel, and Michelle Salathé. 2015. “Authorship in scientific publications: analysis and recommendations." Swiss Medical Weekly. 145: w14108. https://doi.org/10.4414/smw.2015.14108 
Hoey, John. 2000. "Who Wrote This Paper Anyway?: The New Vancouver Group Statement Refines the Definition of Authorship." CMAJ: Canadian Medical Association Journal 163 (6): $716-17$.

Hosseini, Mohammad. 2018. "The Definition of Authorship in the European Code of Conduct for Research Integrity." PUBMET 2018: Scholarly Publishing In The Context Of Open Science, University of Zadar, Zadar, Croatia, 20-21 September 2018. http://pubmet.unizd.hr/pubmet2018/wpcontent/uploads/2018/09/Hosseini_PUBMET2018.pdf

Hosseini, Mohammad, Luca Consoli, Hub Zwart, Mariette van den Hoven. 2019. "Suggestions to Improve the Comprehensibility of Current Definitions of Scientific Authorship for International Authors." Science and Engineering Ethics. https://doi.org/10.1007/s11948-01900106-2

International Committee of Medical Journal Editors. 2019. Recommendations for the Conduct, Reporting, Editing, and Publication of Scholarly Work in Medical Journals. Accessed January 21, 2020. http://www.icmje.org/icmje-recommendations.pdf.

Jones, Anne H. 2003. "Can Authorship Policies Help Prevent Scientific Misconduct? What Role for Scientific Societies?" Science and Engineering Ethics 9 (2): 243-56. https://doi.org/10.1007/s11948-003-0011-3.

Journal of Occupational and Organizational Psychology (JOOP). 2019. JOOP author $\begin{array}{lllll}\text { guidelines. } & \text { Accessed } & \text { June } & \text { 8, }\end{array}$ https://onlinelibrary.wiley.com/page/journal/20448325/homepage/ForAuthors.html

Larivière, Vincent, Nadine Desrochers, Benoît Macaluso, Philippe Mongeon, Adèle Paul-Hus, and Cassidy R Sugimoto. 2016. "Contributorship and Division of Labor in Knowledge Production." Social Studies of Science $46 \quad$ (3): 417-35. https://doi.org/10.1177/0306312716650046.

Lissoni, Francesco, Fabio Montobbio, and Lorenzo Zirulia. 2013. "Inventorship and Authorship as Attribution Rights: An Enquiry into the Economics of Scientific Credit." Journal of Economic Behavior \& Organization 95 (November): 49-69. https://doi.org/10.1016/j.jebo.2013.08.016. 
Marušić, Ana, Bošnjak, Lana, and Jerončić, Ana 2011. “A Systematic Review of Research on the Meaning, Ethics and Practices of Authorship across Scholarly Disciplines." PLOS ONE, 6(9), e23477. https://doi.org/10.1371/journal.pone.0023477

Méndez, David I., and M. Ángeles Alcaraz. 2015. "Exploring Acknowledgment Practices in English-Medium Astrophysics Research Papers: Implications on Authorship." Revista de Lenguas Para Fines Específicos 21 (1): 132-59. http://dx.doi.org/10.20420/rlfe.2015.0007

Mongeon, Philippe, Elise Smith, Bruno Joyal, and Vincent Larivière. 2017. "The Rise of the Middle Author: Investigating Collaboration and Division of Labor in Biomedical Research Using Partial Alphabetical Authorship." PLOS ONE 12 (9): e0184601. https://doi.org/10.1371/journal.pone.0184601.

Resnik, David B. 1997. "A Proposal for a New System of Credit Allocation in Science." Science and Engineering Ethics 3: 237-243.

Shamoo, Adil E. and David B. Resnik. 2015. Responsible Conduct of Research. Third Edition. Oxford: Oxford University Press.

Steneck, Nicholas H. 2006. "Fostering Integrity in Research: Definitions, Current Knowledge, and Future Directions." Science and Engineering Ethics 12 (1): 53-74.

Strange, Kevin. 2008. “Authorship: Why Not Just Toss a Coin?” American Journal of Physiology-Cell Physiology 295 (3): C567-75. https://doi.org/10.1152/ajpcell.00208.2008.

The World Association of Medical Editors (WAME). 2007. “Authorship Guidelines.” 2007. Accessed January 11, 2019. 
Tables

Table 1.

\begin{tabular}{|c|c|c|c|}
\hline & ECCRI & ICMJE & WAME \\
\hline $\begin{array}{l}\text { Conditions } \\
\text { for } \\
\text { Authorship } \\
\text { Credit }\end{array}$ & $\begin{array}{l}\text { Significant } \\
\text { contribution to the: } \\
\text { - Design of the } \\
\text { research; OR } \\
\text { Relevant data } \\
\text { collection; } \\
\text { OR Analysis } \\
\text { OR } \\
\text { interpretation } \\
\text { of results. }\end{array}$ & $\begin{array}{l}\text { Substantial contributions } \\
\text { to the conception OR } \\
\text { design of the work; OR } \\
\text { Acquisition, analysis, OR } \\
\text { interpretation of data; } \\
\text { AND } \\
\text { - Drafting or revising the } \\
\text { manuscript (important } \\
\text { intellectual content); } \\
\text { AND } \\
\text { Final approval of the } \\
\text { version to be published; } \\
\text { AND } \\
\text { Agreement to be } \\
\text { accountable for all } \\
\text { aspects of the work. }\end{array}$ & $\begin{array}{l}\text { - Substanti } \\
\text { al } \\
\text { intellectu } \\
\text { al } \\
\text { contributi } \\
\text { ons to the } \\
\text { study (for } \\
\text { example, } \\
\text { to the } \\
\text { research } \\
\text { question, } \\
\text { design, } \\
\text { analysis, } \\
\text { interpretat } \\
\text { ion, and } \\
\text { written } \\
\text { descriptio } \\
\text { n); AND } \\
\text { Final } \\
\text { approval } \\
\text { of the } \\
\text { version to } \\
\text { be } \\
\text { published }\end{array}$ \\
\hline
\end{tabular}


Table 2.

\begin{tabular}{|c|c|c|c|}
\hline Contributor & ECCRI & ICMJE & WAME \\
\hline Abigail & $\begin{array}{l}\text { Author: } \\
\text { - Significant } \\
\text { contribution } \\
\text { to data } \\
\text { collection }\end{array}$ & $\begin{array}{l}\text { Inconclusive: } \\
\text { The question of whether } \\
\text { they have provided } \\
\text { 'important intellectual } \\
\text { content' when drafting or } \\
\text { revising the manuscript } \\
\text { will depend on the } \\
\text { outcome of the process of } \\
\text { being held accountable }\end{array}$ & $\begin{array}{l}\text { Inconclusive: } \\
\text { The question of whether } \\
\text { they have provided } \\
\text { 'substantial intellectual } \\
\text { contributions' to the } \\
\text { study will depend on the } \\
\text { criteria for 'substantial } \\
\text { intellectual } \\
\text { contributions' that one } \\
\text { employs }\end{array}$ \\
\hline Martin & $\begin{array}{l}\text { Author: } \\
\text { - Significant } \\
\text { contribution } \\
\text { to data } \\
\text { collection }\end{array}$ & $\begin{array}{l}\text { Non-author: } \\
\text { - Did not contribute } \\
\text { to drafting or } \\
\text { revising the } \\
\text { manuscript } \\
\text { - Contribution may } \\
\text { be acknowledged } \\
\text { in the manuscript }\end{array}$ & $\begin{array}{l}\text { Non-author: } \\
\text { - Administrative } \\
\text { contribution that } \\
\text { may be } \\
\text { acknowledged in } \\
\text { the manuscript }\end{array}$ \\
\hline
\end{tabular}


Table 3.

\begin{tabular}{|c|c|c|c|}
\hline Contributor & ECCRI & ICMJE & WAME \\
\hline Robbie & \begin{tabular}{|l} 
Author: \\
- \\
Significant \\
contribution \\
to data \\
collection
\end{tabular} & $\begin{array}{l}\text { Non-author: } \\
\text { - Did not } \\
\text { contribute to } \\
\text { drafting or } \\
\text { revising the } \\
\text { manuscript } \\
\text { - Contribution } \\
\text { may be } \\
\text { acknowledged } \\
\text { in the } \\
\text { manuscript }\end{array}$ & $\begin{array}{l}\text { Non-author: } \\
\text { - Technical } \\
\text { contribution that } \\
\text { may be } \\
\text { acknowledged in } \\
\text { the manuscript }\end{array}$ \\
\hline Jennifer & \begin{tabular}{|l} 
Author: \\
- \\
Significant \\
contribution \\
to data \\
collection
\end{tabular} & $\begin{array}{l}\text { Inconclusive: } \\
\text { The question of whether } \\
\text { they have provided } \\
\text { 'important intellectual } \\
\text { content' when drafting } \\
\text { or revising the } \\
\text { manuscript will depend } \\
\text { on the outcome of the } \\
\text { process of being held } \\
\text { accountable }\end{array}$ & $\begin{array}{l}\text { Inconclusive: } \\
\text { The question of whether } \\
\text { they have provided } \\
\text { 'substantial intellectual } \\
\text { contributions' to the study } \\
\text { will depend on the criteria } \\
\text { for 'substantial intellectual } \\
\text { contributions' that one } \\
\text { employs }\end{array}$ \\
\hline
\end{tabular}

